\title{
Direitos sexuais e reprodutivos na atenção primária à saúde: relato de experiência
}

Ariana Colombari de Godoi Floresta, Karolina Adrienne Silva Oliveira, Vanessa Santos de Souza, Marianne Cabette de Oliveira, Juliana de Oliveira Faria

\begin{abstract}
Resumo
Os direitos sexuais e reprodutivos são partes integrantes dos direitos humanos, e defendem a vivência da sexualidade sem constrangimento, a maternidade voluntária e a contracepção autodecidida. No Brasil, este conceito surge em especial com os movimentos feministas, na década de 1980, trazendo à tona a reflexão de mulheres acerca da reprodução, do seu papel e sua condição na sociedade. Com a implantação do Sistema Único de Saúde no final da década de 1980 a educação em saúde tornou-se uma estratégia importante para alcançar a transformação social, tendo na Atenção Primária à Saúde (APS) um cenário de potência para o agenciamento de práticas voltadas para o exercício dos direitos sexuais e reprodutivos. Relatar uma experiência exitosa de grupo educativo no Programa de Residência Multiprofissional em Saúde da Família do HU/UFJF. Trata-se de um relato de experiência do grupo educativo de diretos sexuais e reprodutivos realizado em uma Unidade de Atenção Primária à Saúde (UAPS) de Juiz de Fora, Minas Gerais. Foram realizados dois encontros em maio de 2016, sob a coordenação de uma equipe interdisciplinar composta por residentes de Enfermagem e Serviço Social, e Agentes Comunitárias de Saúde, com a presença de dezesseis usuários no primeiro dia, sendo sete homens e nove mulheres, e treze no segundo, composto por sete mulheres e seis homens. Cabe ressaltar que as faltas do segundo encontro foram faltas justificadas. Optou-se pela metodologia participativa, mobilizando o conhecimento de todos os integrantes nas atividades propostas. No primeiro encontro foi resgatado o conceito de direitos sexuais e reprodutivos, a questão do sexo/gênero e planejamento familiar, anatomia reprodutiva e métodos naturais. No segundo encontro, foram discutidos os métodos contraceptivos e agendado retorno na UAPS para atendimento individual, no qual uma das ações é o preenchimento do "cartão do homem e/ou da mulher", conferindo acesso aos métodos disponíveis no SUS do município. A metodologia participativa na execução do grupo foi considerada essencial para a adesão dos usuários em ambos os encontros, destacando-se a participação ativa de um número expressivo de homens, o que comumente não se observa nos grupos de direitos reprodutivos. Foi notório o interesse dos participantes acerca da temática, entretanto há uma lacuna de conhecimento em especial no que diz respeito aos aspectos conceituais dos direitos sexuais e reprodutivos. Em relação aos métodos, grande parte do grupo possuía conhecimento prévio e já havia feito uso de pelo menos um deles, sendo o método cirúrgico a opção de escolha de grande parte dos participantes. Estes usuários foram encaminhados para o serviço de referência, e estão sendo acompanhados para efetuar o acesso ao método escolhido. Os grupos educativos são essenciais na APS, pois constituem ferramentas de potência para estimular o protagonismo dos sujeitos sobre situações relacionadas às suas vidas, em especial quando envolvem temáticas como a pautada no presente relato, envolta a questões sociais, econômicas e culturais vistas como tabu pela sociedade, as quais podem ser desmitificadas por meio da participação nos grupos.
\end{abstract}

Descritores: Direitos sexuais e reprodutivos; Atenção primária à Saúde; Educação em Saúde. 